\title{
Evaluation of Anemia Management by Algorithms in Patients with Chronic Kidney Disease Who Are Not Receiving Dialysis
}

\author{
Jenelle Rogers, Marianna Leung, Monica Beaulieu, Adeera Levin, Shelley Burnett, \\ and Anita Zienkiewicz
}

\begin{abstract}
Background: Anemia commonly develops in patients with chronic kidney disease and is strongly associated with adverse clinical outcomes. There are currently no published studies evaluating the efficacy of a nurse-driven anemia-management protocol for patients with chronic kidney disease who are not receiving dialysis.
\end{abstract}

Objectives: To evaluate the efficacy of an anemia-management protocol in terms of achieving hemoglobin and transferrin saturation levels within the target range, as well as associated utilization of medications, relative to individualized dosing of medications by nephrologists.

Methods: An algorithm for nurse-driven management of anemia was introduced in April 2009 at a kidney function clinic in a large urban centre. The charts of patients with chronic kidney disease who were not undergoing dialysis were reviewed before (July to December 2007) and after (July to December 2009) implementation of the protocol. Patients' data for hemoglobin, transferrin saturation, and doses of iron and erythropoiesis-stimulating agents were collected for each of the 6-month study periods.

Results: In total, 390 patients were treated for anemia before and 434 patients after introduction of the protocol. The anemia-management protocol was non-inferior to individualized dosing for maintenance of hemoglobin levels within the target range of 110-120 g/L: percentage of measured levels within target range 33.3\% (485/1456) before versus $34.2 \%$ (504/1472) after (absolute difference 0.9 percentage points, $95 \%$ confidence interval $[\mathrm{CI}]-2.5$ to 4.4$)$. The criteria for non-inferiority were not met for maintenance of transferrin saturation within the target range of $22 \%-50 \%$ : percentage of levels within target range $58.8 \%(374 / 636)$ before versus $56.9 \%$ (403/708) after (absolute difference 1.9 percentage points, $95 \% \mathrm{CI}-3.4$ to 7.2 ). There were no statistically significant differences in mean doses of epoetin alfa, darbepoetin, or iron before and after introduction of the protocol. Similarly, there were no statistically significant differences in number of dose changes for epoetin alfa, darbepoetin, or iron.

Conclusion: The nurse-driven anemia-management protocol was non-inferior to dosing by nephrologists in terms of managing hemoglobin levels. It would be reasonable to use an anemia-management protocol for patients with chronic kidney disease who are not receiving dialysis.

\section{RÉSUMÉ}

Contexte : L'anémie apparaît souvent chez les patients atteints d'une insuffisance rénale chronique et est fortement associée à des résultats cliniques indésirables. À ce jour, aucune étude clinique publiée n’a évalué l'efficacité d'un protocole de prise en charge de l'anémie par les soins infirmiers chez des patients atteints d'une insuffisance rénale chronique non dialysés.

Objectifs : Évaluer l'efficacité d'un protocole de prise en charge de l'anémie quant à l'atteinte des taux visés d'hémoglobine et de saturation de la transferrine ainsi que l'utilisation afférente des médicaments, par rapport à la posologie individualisée prescrite par les néphrologues.

Méthodes : Un algorithme de prise en charge de l'anémie par les soins infirmiers a été mis de l'avant en avril 2009 dans une clinique de néphrologie d'un grand centre urbain. Les dossiers médicaux des patients atteints d'une insuffisance rénale chronique non dialysés ont été analysés avant (de juillet à décembre 2007) et après (de juillet à décembre 2009) la mise en œuvre du protocole. Les données des patients relativement à l'hémoglobine, à la saturation de la transferrine, et aux doses de fer et des agents stimulant l'érythropoï̀se ont été collectées pour chacune des deux périodes de six mois de l'étude.

Résultats : Le nombre total de patients traités pour une anémie était de 390 avant l'introduction du protocole et de 434, après son introduction. Le protocole de prise en charge de l'anémie était non inférieur à la posologie individualisée pour le maintien des taux d'hémoglobine dans la plage des valeurs cibles de 110 à $120 \mathrm{~g} / \mathrm{L}$ : le pourcentage des taux dans cette plage de valeurs était de 33,3\% (485/1456) avant l'introduction du protocole, comparativement à 34,2\% (504/1472), après son introduction (différence absolue de 0,9 point de pourcentage, intervalle de confiance [IC] à $95 \%-2,5$ à 4,4). Cependant, les critères de non-infériorité n'ont pas été satisfaits pour ce qui est du maintien de la saturation de la transferrine dans la plage des valeurs cibles de $22 \%$ à $50 \%$ : le pourcentage des valeurs dans cette plage était de 58,8 \% (374/636) avant l'introduction du protocole, comparativement à 56,9\% (403/708), après son introduction (différence absolue de 1,9 point de pourcentage, IC à $95 \%-3,4$ à 7,2). Il n'y avait pas de différences statistiquement significatives dans les doses moyennes d'époétine alfa, de darbépoétine ou de fer avant ou après l'introduction du protocole. De même, il n'y avait pas de différences statistiquement significatives dans le nombre de modifications de la dose d'époétine alfa, de darbépoétine ou de fer. 
Key words: erythropoietin, darbepoetin, iron, protocol, anemia, chronic kidney disease

Can J Hosp Pharm 2011;64(2):141-146
Conclusion : Le protocole de prise en charge de l'anémie par les soins infirmiers était non inférieur à la posologie prescrite par les néphrologues pour ce qui est de la prise en charge des taux d'hémoglobine. Il serait raisonnable de recourir à un protocole de prise en charge de l'anémie chez les patients atteints d'une insuffisance rénale chronique non dialysés.

Mots clés : érythropoïétine, darbépoétine, fer, protocole, anémie, insuffisance rénale chronique

[Traduction par l'éditeur]

\section{INTRODUCTION}

A nemia commonly develops in patients with chronic kidney disease and is strongly associated with adverse clinical outcomes, ${ }^{1,2}$ including admission to hospital, cardiovascular disease, and death. ${ }^{2,3}$

Erythropoietin deficiency is common among patients with anemia related to chronic kidney disease, and the use of erythropoiesis-stimulating agents (specifically epoetin or darbepoetin) has been shown to reduce the need for blood transfusions. ${ }^{4}$ However, these therapies do carry risks of adverse outcomes, including increased blood pressure and thrombotic complications, and therefore should be administered at the lowest possible dose.

Other potential causes of anemia and contributing disorders should be assessed. For example, iron deficiency anemia is common in this population. In this situation, appropriate iron supplementation is required before initiation of therapy with erythropoiesis-stimulating agents. ${ }^{3}$ Transferrin saturation is an appropriate indicator of the iron that is effectively available for erythropoiesis.

The Kidney Function Clinic at St Paul's Hospital in Vancouver, British Columbia, is an outpatient clinic for patients with chronic kidney disease who are not receiving dialysis. In the past, physicians at the clinic were responsible for determining dosages of erythropoiesis-stimulating agents and iron for all patients with anemia, without use of a specific protocol. In April 2009, a nurse-driven anemia-management protocol was implemented for outpatients at this clinic. This protocol uses titration algorithms for dosing of erythropoiesis-stimulating agents and iron adapted from the anemia management protocol of the British Columbia Provincial Renal Agency.5 In addition, the clinic's protocol is in accordance with the guidelines for managing anemia in chronic kidney disease of the Kidney Disease Outcomes Quality Initiative (KDOQI). ${ }^{6,7}$

Similar protocols are already being used in many institutions for anemia management in patients undergoing hemodialysis. Pharmacist-driven dosing titration of erythropoiesis-stimulating agents and nurse-driven dosing titration of iron in the hemodialysis unit has been shown to be as effective as management of anemia by physicians and has provided more consistent dosing of erythropoiesis-stimulating agents (unpublished data). These results are consistent with the published literature. For example, in a retrospective study, To and others ${ }^{8}$ found that the average dose of erythropoiesis-stimulating agents required and the achievement of target levels for transferrin saturation and hematocrit improved after implementation of an anemia management protocol for patients receiving hemodialysis. In a more recent study involving hemodialysis patients in the Northern Alberta Renal Program, no difference was noted with regard to dose of erythropoiesis-stimulating agents or achievement of target hemoglobin levels before and after implementation of an anemia protocol..$^{9}$ This lack of difference should not be interpreted as a negative outcome of the trial, as it showed equivalence of outcomes between the protocol and standard care.

There are currently no published studies evaluating the efficacy of a nurse-driven anemia management protocol for patients with chronic kidney disease who are not receiving dialysis. The purpose of this study was to evaluate the efficacy of an anemiamanagement protocol in terms of achieving hemoglobin and transferrin saturation levels within target ranges, as well as utilization of medications, relative to individualized dosing of medications by nephrologists.

\section{METHODS}

\section{Study Design}

Patients with chronic kidney disease at a single centre (the Kidney Function Clinic of St Paul's Hospital) were included in this retrospective analysis. During the preprotocol period (July 1 to December 31, 2007), anemia was managed individually by nephrologists. Nurses received orientation on the use of protocols for dosing of erythropoiesis-stimulating agents and iron (see Appendix 1 available online at www.cjhp-online.ca/index.php/ cjhp/issue/view/80/show/Toc) starting in August 2008, and the protocols were implemented in April 2009. During the protocol period (July 1 to December 31, 2009), all cases of anemia were managed by nursing staff according to these protocols. 


\section{Patient Population}

To be eligible for the study, patients had to be attending the Kidney Function Clinic, had to be receiving either iron or erythropoiesis-stimulating agents during the study period, and had to be at least 19 years of age. Patients were ineligible if they were receiving dialysis, if hemoglobin level had been measured more than 12 times during the study period, or if transferrin saturation level had been measured more than 6 times during the study period. Patients with frequent measurement of these markers were excluded because these patients may have had other causes for anemia and should have been assessed by a nephrologist.

All of the patients meeting these criteria were included in the study. However, the same patients were not necessarily included in both the preprotocol and protocol study periods because patients continually leave the Kidney Function Clinic for various reasons, such as initiation of dialysis, transplant, or death, with new patients joining the program to take their places.

\section{Outcomes}

The primary end points were the percentage of measured hemoglobin and transferrin saturation levels within target range (110-120 g/L and $22 \%-50 \%$, respectively) in the preprotocol and protocol study periods. Transferrin saturation was assessed, rather than ferritin, because it is as reliable a surrogate marker in the predialysis setting. In the anemia-management protocol, the lower limit for transferrin saturation was set at $22 \%$ to ensure that iron status would be optimized in predialysis patients before initiation of erythropoiesis-stimulating agents. The secondary end points were the mean weekly dose and the mean number of dose changes for epoetin alfa, darbepoetin, and iron in the preprotocol and protocol study periods.

\section{Data Collection}

All patients attending the Kidney Function Clinic during the study periods who met the inclusion criteria (and were not excluded by the exclusion criteria) were determined from a list generated by the Patient Records and Outcome Management Information System (PROMIS) support team at the BC Provincial Renal Agency.

The following data were collected from the PROMIS database for each patient enrolled in the study: age, sex, baseline estimated glomerular filtration rate, all hemoglobin and transferrin saturation levels measured, and all erythropoiesisstimulating agents and iron doses (oral and IV) given during the study periods. To ensure patient confidentiality, no patient identifiers were requested from the PROMIS database.

\section{Statistical Analysis}

A sample size was not calculated. The convenience sample was limited to the number of patients attending the Kidney Function Clinic during the study period who met the study criteria. The primary study hypothesis was that the nurse-driven anemia-management protocol was non-inferior to management by a nephrologist with respect to achievement of hemoglobin and transferrin saturation levels within the target range. The selected margin of non-inferiority was an absolute difference of 5 percentage points for both markers. A 2-sided 95\% confidence interval (CI) was calculated around the absolute difference for each of these values.

All of the secondary end points were superiority end points. The Student $t$ test was used to compare the mean weekly doses of erythropoiesis-stimulating agents and iron and the mean number of dosing changes for these medications during the preprotocol and protocol study periods. Values of $p$ less than 0.05 were considered significant. All analyses were performed in Excel, and an intention-to-treat analysis was used.

\section{RESULTS}

Through the PROMIS database, 644 and 832 patients with chronic kidney disease who were not receiving dialysis were identified in the preprotocol and protocol study periods, respectively. A total of 652 patients were excluded on the basis of the predefined criteria, which left 390 patients in the preprotocol study period and 434 patients in the protocol study period (Figures 1 and 2, respectively). At least 90\% of patients in both groups were receiving iron, whereas $186(47.7 \%)$ of the 390 patients in the preprotocol period and 185 (42.6\%) of the 434 patients in the protocol period were receiving erythropoiesisstimulating agents (Table 1).

\section{Primary End Points}

The anemia management protocol was non-inferior to individualized dosing by nephrologists in maintaining hemoglobin levels within target range of $110-120 \mathrm{~g} / \mathrm{L}$. The absolute difference in percentage of hemoglobin measurements within the target range between the study periods was 0.9 percentage points ( $95 \%$ CI -2.5 to 4.4$): 33.3 \%$ (485/1456) for the preprotocol study period and $34.2 \%(504 / 1472)$ for the protocol study period (Figure 3). In terms of transferrin saturation measurements within the target range of $22 \%-55 \%$, the criteria for non-inferiority were not met. The absolute difference in percentage of transferrin saturation levels within the target range between the study periods was 1.9 percentage points (95\% CI -3.4 to 7.2 ): $58.8 \%$ (374/636) for the preprotocol study period and $56.9 \%$ (403/708) for the protocol study period (Figure 3). 


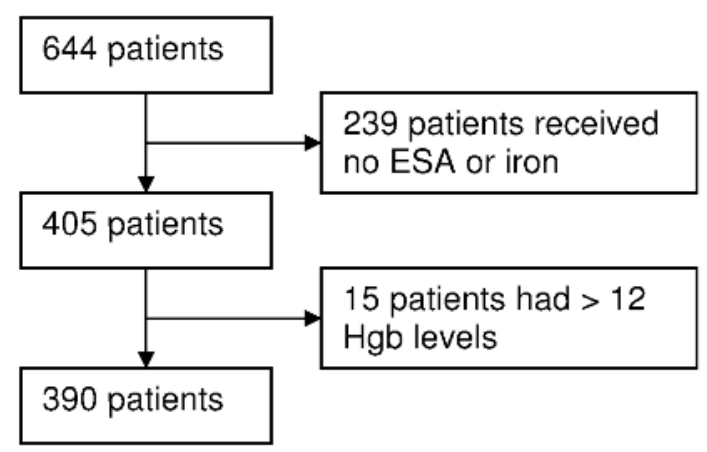

Figure 1. Patient eligibility during the preprotocol period. ESA = erythropoiesis-stimulating agent $\mathrm{Hgb}=$ hemoglobin.

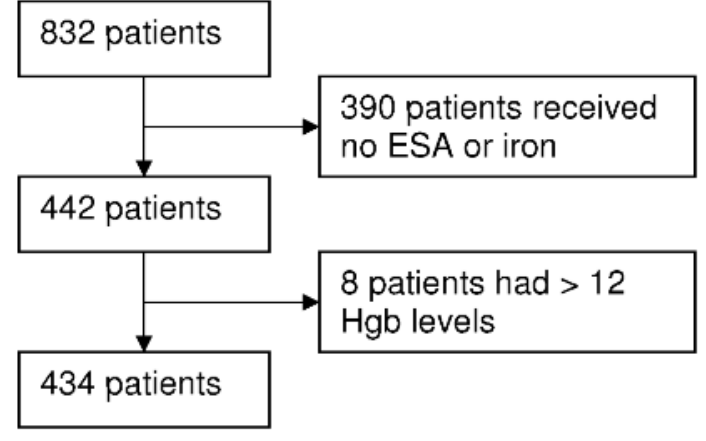

Figure 2. Patient eligibility during the protocol period. ESA = erythropoiesis-stimulating agent $\mathrm{Hgb}=$ hemoglobin.

\section{Table 1. Baseline Characteristics of Patients with Chronic Kidney Disease Not Receiving Dialysis}

\begin{tabular}{lcc} 
Characteristic & $\begin{array}{c}\text { Preprotocol Period } \\
(\boldsymbol{n}=\mathbf{3 9 0})\end{array}$ & $\begin{array}{c}\text { Protocol Period } \\
(\boldsymbol{n}=\mathbf{4 3 4 )}\end{array}$ \\
\hline Age (years), mean \pm SD & $68.4 \pm 14.0$ & $69.5 \pm 13.6$ \\
Sex, no. (\%) male & $214(54.9)$ & $240(55.3)$ \\
Baseline eGFR (mL/min) & $27.6 \pm 11.1$ & $26.9 \pm 11.4$ \\
Received iron, no. (\%) & $350(90.0)$ & $400(92.2)$ \\
Received ESA, no. (\%) & & \\
Epoetin & $134(34.4)$ & $144(33.2)$ \\
Darbepoetin & $52(13.3)$ & $41(9.4)$ \\
\hline
\end{tabular}

eGFR = estimated glomerular filtration rate, ESA = erythropoiesis-stimulating agent SD = standard deviation.

Although not a prespecified outcome, there was also a trend toward a greater percentage of hemoglobin levels being above the target range before introduction of the protocol $(47.1 \%$ [686/1456] versus $35.3 \%[520 / 1472])$.

\section{Secondary End Points}

There was no statistically significant difference in the mean dose of epoetin alfa (3270 units versus 3529 units, $p=0.85$ ), darbepoetin $(18.8 \mu \mathrm{g}$ versus $20.4 \mu \mathrm{g}, p=0.59)$, or iron (1044 $\mathrm{mg}$ versus $1042 \mathrm{mg}, p=0.98$ ) between the preprotocol and protocol study periods. Similarly, there was no statistically significant difference in the mean number of dose changes for epoetin alfa ( 0.4 versus $0.5, p=0.11)$, darbepoetin ( 0.6 versus $0.6, p=0.83)$, or iron ( 0.3 versus $0.3, p=0.55)$ between the preprotocol and protocol study periods.

\section{DISCUSSION}

This study was designed as a non-inferiority study because both nurses and nephrologists at the Kidney Function Clinic prefer the use of a nurse-driven anemia-management protocol. Previous studies of the use of anemia-management protocols for patients who are receiving dialysis have had positive results ${ }^{8,9}$ (unpublished data). The margin of non-inferiority chosen for both primary end points was an absolute difference of 5 percentage points. In the opinion of the study investigators, this value represented the lowest clinically significant difference. However, it is not certain what difference in the percentage of hemoglobin and transferrin saturation levels within target is associated with improvement in clinical outcomes.

Interestingly, although the anemia-management protocol was non-inferior to management by a nephrologist in terms of hemoglobin levels, only about one-third of all hemoglobin measurements were within the target range. This suggests that it is difficult to achieve the narrow therapeutic range for this marker. In the preprotocol study period, $47.1 \%$ of hemoglobin measurements were above the target range (i.e., > $120 \mathrm{~g} / \mathrm{L}$ ), whereas this proportion was $35.3 \%$ in the protocol phase. This finding was expected as a result of a change in practice trending toward the targeting of lower hemoglobin levels. Following several landmark trials, ${ }^{10,11}$ the KDOQI clinical practice guidelines and recommendations for anemia of chronic kidney disease were updated in 2007 to incorporate a new upper limit on target hemoglobin $(120 \mathrm{~g} / \mathrm{L}){ }^{7}$ The Trial to Reduce Cardiovascular Events with Aranesp Therapy (TREAT), ${ }^{12}$ 


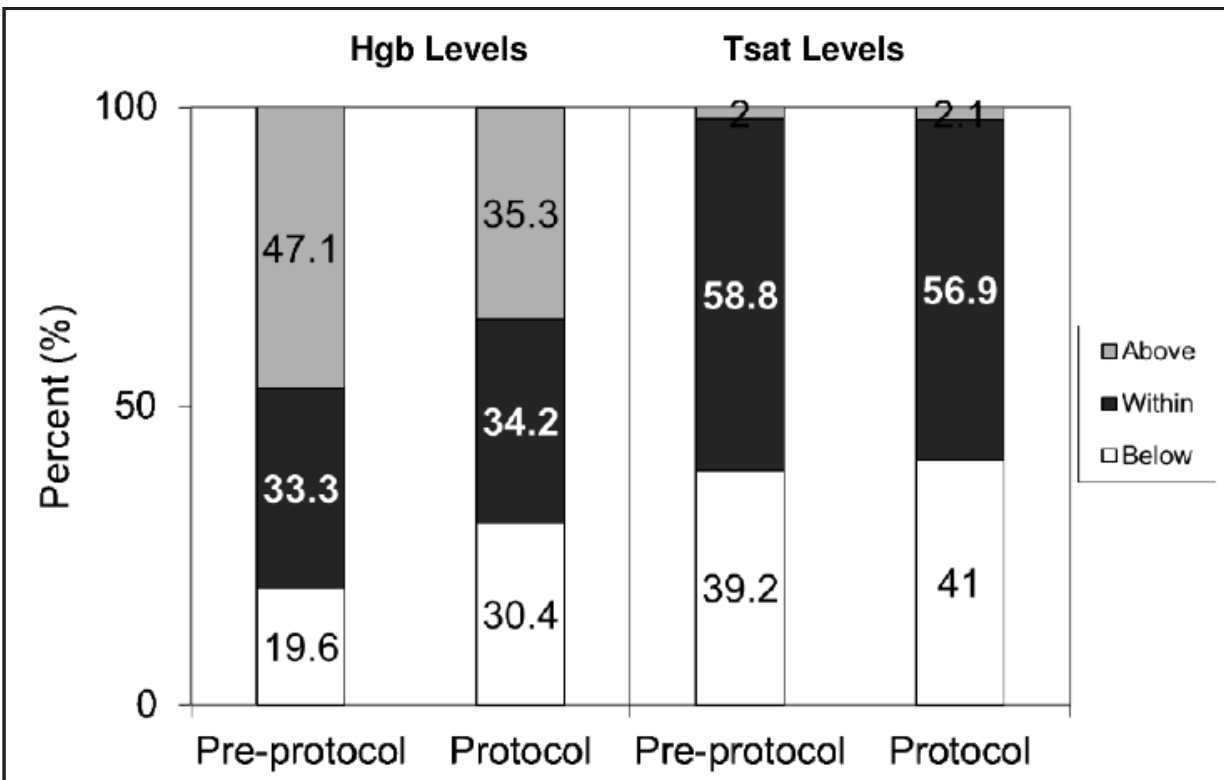

Figure 3. Percentage of patients with hemoglobin ( $\mathrm{Hgb}$ ) and transferrin saturation (Tsat) levels above, within, and below target range.

published in December 2009, suggested that lower targets may be safer. However, the ideal target range for hemoglobin is still under debate. At the time of writing (late 2010), the protocol used by the Kidney Function Clinic was undergoing review with consideration of a lower target range for hemoglobin.

Non-inferiority criteria were not met for the percentage of transferrin saturation levels within the target range. This result is difficult to interpret because this marker is a surrogate end point. Again, the margin of non-inferiority chosen was 5 percentage points; however, this is rather conservative. It is unknown if a larger difference correlates with worse clinical outcomes.

This study had several limitations. A randomized controlled design would have been preferable to a retrospective analysis. However, a parallel randomized controlled design might have resulted in contamination between the individualized dosing (preprotocol) and algorithm dosing (protocol) groups. Data were extracted from the PROMIS database and were not verified with a chart review. Specific causes of anemia, such as admission to hospital, gastrointestinal bleeding, infection, or cancer, could not be identified through this database analysis. With the large number of patients included in the study, adherence and complication rates were assumed to be similar in the 2 groups, but these similarities were not verified. The goal of this study was to determine if the anemiamanagement protocol was useful in a real-life setting. However, patients with anemia that is difficult to manage and who undergo more frequent blood work should receive individualized care from a nephrologist; their care should not be managed by means of an algorithm. Another limitation is that surrogate end points (hemoglobin and transferrin saturation levels), rather than clinical outcomes (such as admission to hospital, need for transfusion, or death), were used as the primary end points. Given the limited time available for data collection (6 months for each study period) and the results of similar studies, it was unlikely that meaningful clinical outcomes could have been identified. However, 6 months of data collection is sufficient to assess anemia in terms of hemoglobin and transferrin saturation levels, because the lifespan of red blood cells is shorter in patients with chronic kidney disease, hemoglobin levels were routinely checked every month, and transferrin saturation levels were checked every 3 months.

\section{CONCLUSIONS}

This study showed that the nurse-driven anemiamanagement protocol at the Kidney Function Clinic of St Paul's Hospital is non-inferior to individualized management of anemia by nephrologists, in terms of hemoglobin levels within the target range. Although non-inferiority criteria were not met for transferrin saturation levels within the target range, the margin of non-inferiority may have been too conservative. Therefore, the Kidney Function Clinic will continue to use a nurse-driven anemia-management protocol, although the specific protocol published in this study will be continually reviewed and updated in accordance with new literature and guidelines that become available. This approach is now preferred by both nurses and nephrologists working in the clinic and is a more cost-effective allocation of resources. 


\section{References}

1. Levin A, Hemmelgarn B, Culleton B, Tobe S, McFarlane P, Ruzicka M, et al. Guidelines for the management of chronic kidney disease. CMAJ 2008;179(11):1154-1162.

2. Smith C, Da Silva-Gane M, Chandna S, Warwicker P, Greenwood R, Farrington K. Choosing not to dialyze: evaluation of planned non-dialytic management in a cohort of patients with end-stage renal failure. Nephron Clin Pract 2003;95:c40-c46.

3. Van Manen JG, Korevaar JC, Dekker FW, Boeschoten EW, Bossuyt PM, Krediet RT; NECOSAD-Study Group. Adjustment for comorbidity in studies on health status in ESRD patients: which comorbidity index to use? J Am Soc Nephrol 2003;14(2):478-485.

4. Lawler EV, Bradbury BD, Ronda JR, Gaziano JM, Gagnon DR. Transfusion burden among patients with chronic kidney disease and anemia. Clin J Am Soc Nephrol 2010;5(4):667-672.

5. Renal anemia management protocol. Vancouver (BC): British Columbia Provincial Renal Agency; [cited 2009 Jul 29]. Available from: www. bcrenalagency.ca/NR/rdonlyres/4B14D840-9DA0-4314-A22E037B6A33A0C4/25133/ AnemiaProtocolweb.pdf

6. National Kidney Foundation. KDOQI clinical practice guidelines and clinical practice recommendations for anemia in chronic kidney disease. Am J Kidney Dis 2006;47 Suppl 3:S1-S145.

7. National Kidney Foundation. KDOQI clinical practice guidelines and clinical practice recommendations for anemia in chronic kidney disease: 2007 update of hemoglobin target. Am J Kidney Dis 2007;50(3):471-530.

8. To LL, Stoner CP, Stolley SN, Buenviaje JD, Ziegler TW. Effectiveness of a pharmacist-implemented anemia management protocol in an outpatient hemodialysis unit. Am J Health Syst Pharm 2001;58(21):2061-2065.

9. Nhan J, Jensen L, McMahon A. Evaluation of an anemia algorithm in chronic hemodialysis patients. CANNT J 2007;17(3):48-58, 62-73.

10. Drüeke TB, Locatelli F, Clyne N, Eckardt KU, Macdougall IC, Tsakiris $\mathrm{D}$, et al; CREATE Investigators. Normalization of hemoglobin level in patients with chronic kidney disease and anemia. N Engl J Med 2006;355(20):2071-2084.
11. Singh AK, Szczech L, Tang KL, Barnhart H, Sapp S, Wolfson M, et al; CHOIR Investigators. Correction of anemia with epoetin alfa in chronic kidney disease. N Engl J Med 2006;355(20):2085-2098.

12. Pfeffer MA, Burdmann EA, Chen CY, Cooper ME, de Zeeuw D, Eckardt $\mathrm{KU}$, et al; TREAT Investigators. A trial of darbepoetin alfa in type 2 diabetes and chronic kidney disease. N Engl J Med 2009;361(21):2019-1032.

Jenelle Rogers, BScChem, BScPharm, ACPR, is a Clinical Pharmacist, St Paul's Hospital, Providence Healthcare, Vancouver, British Columbia.

Marianna Leung, BScPharm, ACPR, PharmD, is a Clinical Pharmacy Specialist, St Paul's Hospital, Providence Healthcare, Vancouver, British Columbia.

Monica Beaulieu, MD, is a nephrologist, St Paul's Hospital, Providence Healthcare, Vancouver, British Columbia.

Adeera Levin, MD, is a nephrologist, St Paul's Hospital, Providence Healthcare, Vancouver, British Columbia.

Shelley Burnett, RN, is a Registered Nurse, St Paul's Hospital, Vancouver, British Columbia.

Anita Zienkiewicz, RN, is a Registered Nurse, St Paul's Hospital, Vancouver, British Columbia.

Address correspondence to:

Dr Marianna Leung

Pharmacy Department

St Paul's Hospital

1081 Burrard Street

Vancouver BC V6Z 1 Y6

e-mail: mleung@providencehealth.bc.ca 